Archived version from NCDOCKS Institutional Repository http://libres.uncg.edu/ir/asu/

\title{
Appalachỉan
}

B O O NE, NORTH CAROLINA

\section{Microbial Sequencing Analyses Suggest the Presence of a Fecal Veneer on Indoor Climbing Wall Holds}

By: S. L. Brauer,D. Vuono, M. J. Carmichael, C. Pepe-Ranney, A. Strom, E. Rabinowitz, D. H. Buckley \& S. H. Zinder

\begin{abstract}
Artificial climbing walls represent a unique indoor environment in which humans interact closely with a variety of surface types. Climbing wall holds may mediate transmission of organisms between individuals, and yet there are no studies that identify microorganisms present on these surfaces. In the current study, the micro-organisms found on climbing wall holds were characterized by analysis of amplified SSU rRNA gene sequences. In contrast to many other studies of built environments, the majority of microorganisms on holds were most closely related to microbes annotated as being recovered from environmental sources, such as soil, with human skin also representing an important source. Regional patterns were evident as rRNA gene sequences from the marine cyano-bacterium Prochlorococcus were abundant in gyms found within $16 \mathrm{~km}$ of the ocean. Enterobacteriaceae were present on $100 \%$ of holds surveyed, and the members detected are commonly associated with fecal matter.
\end{abstract}

S. L. Brauer,D. Vuono, M. J. Carmichael, C. Pepe-Ranney, A. Strom, E. Rabinowitz, D. H. Buckley \& S. H. Zinder (2014) "Microbial Sequencing Analyses Suggest the Presence of a Fecal Veneer on Indoor Climbing Wall Holds" Current MicroBiology Volume 69 Issue 5 pp. 681-689 Version of Record Available From www.academia.edu 


\section{Introduction}

In Western countries, most people spend the vast majority of their lives indoors [33, 34]. Microorganisms within these built environments can be introduced by people, pets, food, water, and air [4], and recent studies have indicated that humans (particularly skin, nostrils, and hair) are the primary contributors to microbial communities in classrooms [28], kitchens [21], bathrooms [20], office buildings [26, 46], subway systems [47], shopping centers [52], and hospitals [27, 32]. Indeed, temporal changes in aerosolized microbial load have been correlated with human density in subway systems [16]. Similarly, human-associated bacteria were relatively more abundant in occupied versus unoccupied classrooms at the University of Oregon [38], emphasizing the importance of human presence in contributing to microbial dispersal in indoor environments.

Climbing gyms are a unique environment where climbers tightly grip handholds that generally have a rough 
surface much like sandpaper. While the surface allows for better grip, it can also lead to tears in the skin. Such abrasions may allow an entry point for pathogens [51] or may make the transfer of blood borne pathogens a possible, albeit unlikely, concern [50]. Outbreaks of communityacquired bacterial infections have been previously associated with athletes and equipment used in athletic facilities $[2,6,10-12,42]$. Possible vectors of transmission in these cases include skin-to-skin contact, abrasions/skin damage, respiratory pathways, sharing of equipment such as hygiene products and clothing, and contact with surfaces such as mats, pads, weights, and exercise equipment [12]. Both hands and surfaces have been implicated in transmission of potential pathogens such as methicillin-resistant [25] and/or methicillin-sensitive staphylococci [54], Klebsiella spp. [9], fecal bacteria [29], and viruses [24, 36, 37, 39]. Although there is debate in the literature regarding the relative role of skin-to-skin contact versus environmental surface contact in the transmission of infection in athletic settings $[3,5,11]$, climbing holds may represent a potential reservoir for pathogens. However, we know almost nothing about dispersal of microorganisms from sources such as hands, climbing shoes, or air onto climbing holds.

\section{Materials and Methods}

\section{Sample Collection}

A total of 12 handholds were sampled across 4 climbing gyms (3 holds/gym) in March-June of 2011. Three climbing gyms are located within southern Massachusetts and Rhode Island ( $\mathrm{Y}, \mathrm{H}$, and $\mathrm{C})$, and all three are within $16 \mathrm{~km}$ of the ocean. In contrast, the fourth is located in the mountains of North Carolina (SLB), roughly $500 \mathrm{~km}$ from the ocean. Prior to sampling, all climbing gym establishments were made aware of the nature of the investigation through written and verbal consent, and it was agreed that the identities of the facilities would be kept anonymous. Handholds were selected based on the criteria that (1) each hold represented the beginning of a climbing route and (2) had not been cleaned by employees for at least 1 month. Handhold surfaces were thoroughly swabbed with sterile cotton-tipped swabs moistened with sterile phosphate buffered saline (PBS). Following sampling, each swab tip was aseptically placed in a sterile $2 \mathrm{ml}$ cryogenic vial and stored on ice for temporary storage $(<12 \mathrm{~h})$, followed by $-20{ }^{\circ} \mathrm{C}$ overnight storage.

DNA Extraction, PCR, and DNA Sequencing

Each swab tip was transferred with sterile tweezers to a bead tube and DNA extracted from each swab using the
Fast DNA Spin Kit for Soil (MP Biomedicals, Solon, OH) following manufacturer's protocol, except that bead tubes were heated at $65{ }^{\circ} \mathrm{C}$ for $10 \mathrm{~min}$, prior to bead beading [18]. PCR reactions were carried out for a total of 32 cycles with a total reaction volume of $30,2 \mu \mathrm{l}$ of which was DNA template. Reagents and final concentrations were $1 \times$ Phusion HF polymerase ( $2 \mathrm{X}$ mastermix; Finnzymes) with $8 \% \mathrm{v} / \mathrm{v}$ DMSO and $0.5 \mu \mathrm{M}$ forward and reverse primers in the final reaction volume. PCR thermal cycling conditions consisted of an initial denaturation and enzyme activation at $98^{\circ} \mathrm{C}$ for $1 \mathrm{~min}$, followed by 22 cycles of 3-step PCR: denaturation $\left(98{ }^{\circ} \mathrm{C}\right.$ for $5 \mathrm{~s}$ ), annealing (touchdown $68-58{ }^{\circ} \mathrm{C}$ at $1{ }^{\circ} \mathrm{C} /$ cycle for $10 \mathrm{~s}$ for the initial 10 cycles and remaining 12 cycles held constant at $58{ }^{\circ} \mathrm{C}$ ), and elongation $\left(72{ }^{\circ} \mathrm{C}\right.$ for $\left.7 \mathrm{~s}\right)$. Touchdown PCR was employed in order to minimize primer-dimer formation. The last 10 cycles consisted of a 2 -step PCR with denaturation $\left(98^{\circ} \mathrm{C}\right.$ for $\left.5 \mathrm{~s}\right)$ and annealing/elongation $\left(72{ }^{\circ} \mathrm{C}\right.$ for $21 \mathrm{~s}$ ). PCR products were quantified using the PicoGreen dsDNA reagent (Invitrogen) and were gel purified using the Montage Kit (Millipore). Modified small sub-unit (SSU) rRNA gene primers 515f-927r were incorporated with adapter sequences for the GSFLX-Titanium platform of the Roche 454 Pyrosequencing technology as described previously [41]. The modified SSU rRNA gene primers were as follows: 515f-modified, 5'-GTGYCAGCMGCCG CGGTAA- ${ }^{\prime}$ and 927r-modified, 5'-CCGYCAATT CMT TTRAGTTT- $3^{\prime}$. Additionally, the relative abundance of members of the family Enterobacteriaceae was verified for hold SLB2 using protocols adapted from [19]. In this case, amplicons from three separate PCR reactions using the $27 \mathrm{f}$ and $338 \mathrm{r}$ primers [18] were pooled and cloned using a TOPO TA $p c r^{\circledR} 2.1$ vector kit (Invitrogen, Carlsbad, CA). Approximately, 150 colonies were sent to BeckmanCoulter Genomics (Danvers, MA) to be purified and sequenced using a Sanger platform. Taxonomic analyses for the Sanger sequences were conducted using the RDP classifier.

\section{Data Analysis and Quality Control}

Sequences generated from pyrosequencing of SSU rRNA gene amplicons were binned by barcode and quality filtered using the "split_libraries.py" script in the Quantitative Insights Into Microbial Ecology (QIIME v1.5) software [8]. Discarded sequences included those with errors in the barcode or primer, shorter than $250 \mathrm{nt}$, longer than $600 \mathrm{nt}$, with a quality score $<50$, with a homopolymer run greater than $6 \mathrm{nt}$, and those which contained ambiguous base calls. Flowgrams for remaining sequences were denoised using DeNoiser version 1.3.0-dev by [44]. Chimeric sequences were identified using UCHIME under reference mode (Edgar et al. 2011). Given that chimeric sequences were 
most likely among the less abundant sequences, the abundant sequences of cluster sizes $>20$ that were flagged as chimeras were hand checked against the NCBI nt database using BLAST [1]. Query sequences with mismatches on either end compared to a reference sequence were split at the point where reference and query sequences appeared to diverge. Each end of the split sequence was reBLASTed, and sequences that did not demonstrate taxonomic consistency were discarded. The remaining sequences (23,985 total) were processed in Mothur [48] as outlined by [49, SOP version date 2/15/2013]. Briefly, we aligned to the SILVA bacterial reference alignment using NAST [13]; those sequences that did not begin at the V4 region and terminate at the end of the V5 region were discarded from further analysis. Vertical gaps were removed from the alignment, and leading and trailing columns were discarded such that no sequences had terminal gaps (vertical $=\mathrm{T}$ and trump $=$., options in Mothur). Taxonomic classification of all remaining sequences was implemented using the RDP Classifier [53] at $80 \%$ bootstrap confidence. The RDP Classifier was trained with the greengenes SSU rRNA database (DeSantis et al. 2006). Sequences were clustered into operational taxonomic units (OTUs) at $97 \%$ identity using the average neighbor method (Mothur) with pairwise distances calculated from the multiple sequence alignment described above. The consensus taxonomy was assigned to OTU clusters using the classify.otu command in Mothur. Singletons were also discarded for downstream analysis. A phylogenetic tree was constructed from the filtered alignment using FastTree. Unweighted UniFrac, weighted UniFrac, and Bray-Curtis distance matrices were calculated and were visualized using principal coordinates analysis (http://www.r-project. org). Beta diversity metrics were derived from a rarefied OTU table at a depth of 461 sequences, corresponding to the sample with the lowest library size, H3 [22]. Phylogenetic analyses were conducted by first generating alignments using the online SILVA aligner [43]. Dendrograms were constructed using neighbor-joining and maximumlikelihood methods in the PHYLIP software package [17]. Exploration of potential sources for handhold-derived sequences was accomplished by recruiting sequences recovered in this study to annotated sequences in the Silva SSU_Ref111 SSU rRNA gene database. The "isolation source" field in SSU_Ref111 was used to find reference sequences putatively derived from soil, skin, or marine environments. Our sequences were then BLASTed against SSU_Ref111 sequences annotated as being isolated from "soil", "skin", or "marine" environments to determine the isolation source of the closest reference match. Sequences that did not have a reference match within $95 \%$ sequence identity were categorized as "no blast hit". Sequences were deposited into the BioSample database under project
Table 1 Phylum-level representation of sequences found on climbing holds

\begin{tabular}{ll}
\hline Phylum & Percentage of sequences \\
\hline Proteobacteria & 40.8 \\
Firmicutes & 21.9 \\
Cyanobacteria & 12.7 \\
Bacteroidetes & 8.0 \\
Actinobacteria & 6.9 \\
Acidobacteria & 1.8 \\
Planctomycetes & 1.7 \\
Armatimonadetes (formerly OP10) & 0.65 \\
Deinococcus-Thermus & 0.63 \\
Chlorobi & 0.45 \\
Spirochaetes & 0.38 \\
Fusobacteria & 0.27 \\
Other Phyla $(<0.1 \%)$ & 2.1 \\
Unclassified & 1.5 \\
\hline
\end{tabular}

identification number PRJNA207668. The top 15 OTUs as well as OTU 271 and OTU 763 were given accession numbers SAMN02296807-SAMN02296824.

\section{Results and Discussion}

\section{General Findings}

After removing sequences of insufficient quality or length, 20,500 sequences remained with an average length of 373 bp. Overall, an average of 1,708 (range 461-3,951) sequences was obtained for each of the 12 climbing holds sampled. A total of 546 OTUs, with an average of 158 (range 63-271) operational taxonomic units (OTUs), were obtained from each handhold at a $97 \%$ cutoff. Sequences were distributed across five to seven main phyla (defined as phyla representing more than $1-5 \%$ of the population): Proteobacteria, Firmicutes, Cyanobacteria, Bacteroidetes, Actinobacteria, Acidobacteria, and Planctomycetes (Table 1). At the phylum level, climbing gym handholds appeared to harbor more diversity compared to human hands, which are dominated by three to four phyla: Firmicutes, Bacteroidetes, Actinobacteria, and Proteobacteria $[14,18]$. The greater phylum-level diversity obtained here is not due to greater sequencing depth, since the Fierer et al. [18] study had greater sequencing depth than our study (an average of 3,251 sequences per palm versus an average of 1,708 sequences per handhold in our study). Instead, the source of this phylum-level diversity likely reflects contact with soil on climbing shoes and exposure to dust from the air and other environmental sources. For example, climbing holds contained more than twenty-five 
Fig. 1 Exploration of potential sources for handhold-derived sequences. Sequences were recruited to sequence groups annotated as being obtained from the following environments: soil, skin, marine, or other environments (no blast hit). $C, H$, and $Y$ represent the Boston-area gym samples, and SLB represents samples from the rural area gym. Numbers indicate the swab number that was sequenced (out of six collected)
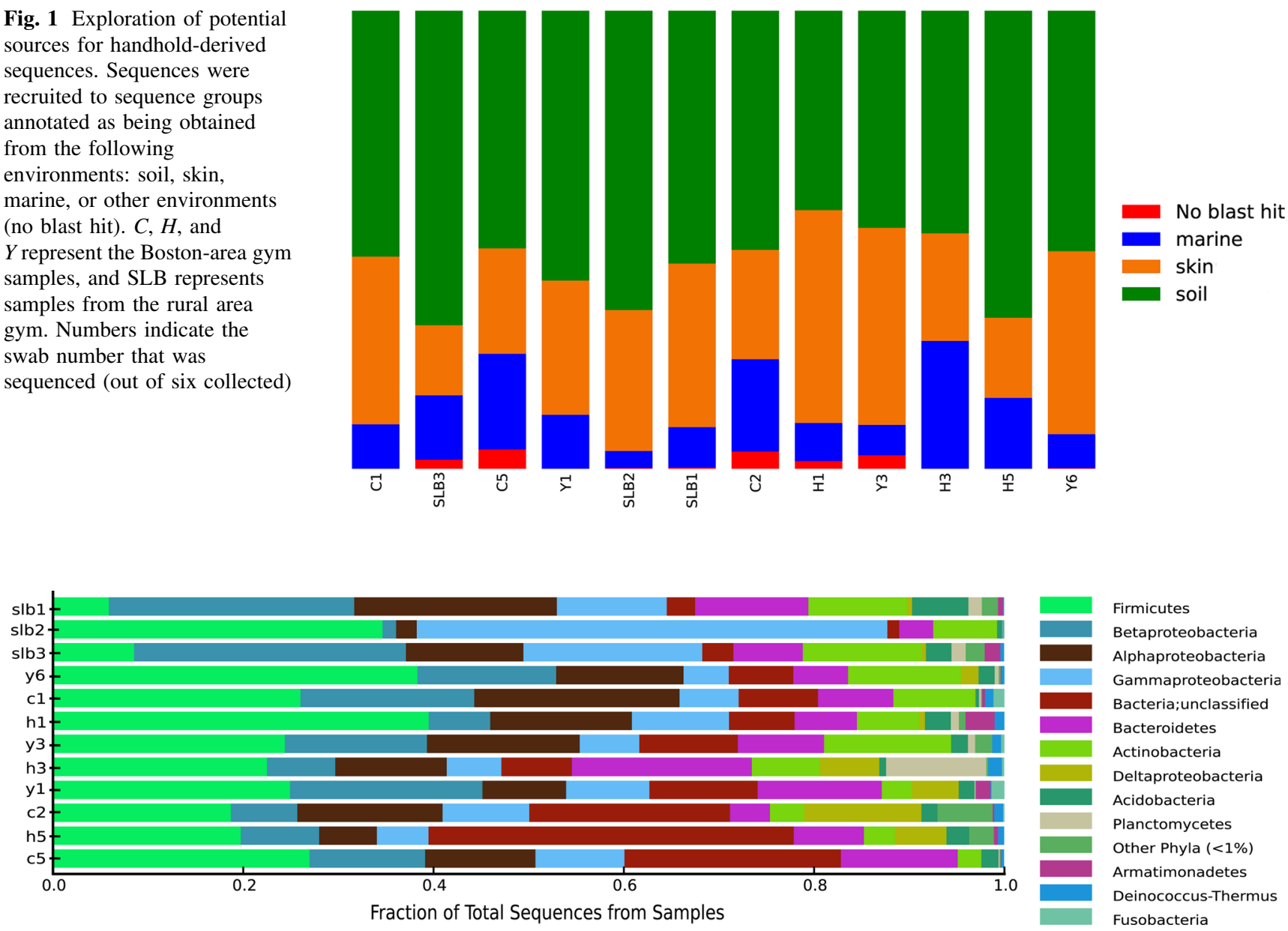

Fig. 2 Distribution of sequences (by phylum) across all 12 handholds. Taxonomic classification was assigned using the RDP classifier and retrained with the Greengenes taxonomy

phyla (data not shown), and at least two of the main phyla (represented by $>1 \%$ of sequences) are uncommon on hands: Acidobacteria, which are common in soil environments and Planctomycetes, which are common in soils and aquatic environments (Table 1; Fig. 2). In contrast, the nine additional phyla commonly detected on skin include Cyanobacteria, Chlamydiae, Deinococcus, Deferribacteres, Thermus, Fusobacteria, Spirochaetes, Verrucomicrobia, and the candidate phyla TM7 and SR1 [14].

\section{Environmental Signatures}

Many sequences obtained in this study appear to have come from non-skin sources; moreover, the majority of these sequences matched sequences obtained from soil (Fig. 1). For example, some of the most abundant OTUs, such as those assigned to Comamonadaceae or Ralstonia (Fig. 2; Table 2), matched sequences detected in soils or marine sediments. Further, many of the sequences assigned to Acidobacteria shared high identity (99-100\%) with sequences from soil. For example, OTU 271 shared $99 \%$ identity with grassland soil clone SEG 08030 [Accession HQ597748, 40]. It is likely that soil-related organisms may have been transferred to the climbing wall from the shoes of climbers. This is in contrast to studies of indoor environments which generally find an abundance of skin-related sequences [see review by 31] and is more in line with studies of outdoor air [7].

Additionally, sequences assigned to the cyanobacterial family Gomphosphaeriaceae, which are found primarily in freshwater habitats [45], were also more abundant (up to $9 \%$ ) in two of the three inland (non-coastal) gym samples compared to $0.1-3 \%$ in two of the nine Boston, MA-area samples. Even more apparent was the prevalence of marine Prochlorococcus sequences in samples from the coastal (Boston, MA-area) climbing gyms representing up to $20 \%$ of sequences on 6 of the 9 holds, compared to the inland gym samples where this OTU was not detected (OTU 4, Figs. 3, 4). These data corroborate data from a recent study of bacterial diversity in office spaces that found an 
Table 2 Identification of the 15 most abundant OTUs found on climbing wall holds

\begin{tabular}{|c|c|c|c|}
\hline Taxon & $\begin{array}{l}\text { Abundance } \\
(\%)\end{array}$ & OTU & Top BLAST hits (Accession, \% ID) \\
\hline Escherichia_g & 9 & 232 & $\begin{array}{l}\text { Shigella flexneri strain CCAM } 090021 \text { (KC429777, } 100 \%) \text { Escherichia coli O157:H7 str. Sakai strain } \\
\text { (NR_074891, } 100 \%) \text { E. coli O169:H-associated w/traveler's diarrhea (AB604197, 100 \%) }\end{array}$ \\
\hline Staphylococcus_s & 8 & 358 & $\begin{array}{l}\text { Staphylococcus warneri strain Lad_25 K (KC354484, } 100 \%) \text { Staphylococcus epidermidis strain BY3 } \\
(\mathrm{KC} 331168,100 \%)\end{array}$ \\
\hline Streptococcus_g & 5 & 74 & $\begin{array}{l}\text { Streptococcus sp. THG-M4 (JX981959, } 100 \text { \%) Streptococcus oralis strain HV 0s122 (JQ782211, } \\
100 \% \text { ) }\end{array}$ \\
\hline Cyanobacteria_c & 4 & 1 & $\begin{array}{l}\text { Enrichment culture clone F44x_D8_T3_E05 (JN569059, } 100 \% \text { ) DGGE gel band C6 lobster } \\
\text { hemolymph (GQ255454, 100\%) }\end{array}$ \\
\hline Comamonadaceae_f & 4 & 156 & $\begin{array}{l}\text { Water-flooding petroleum reservoir clone S6B_101 (JQ433727, } 100 \%) \text { Skin microbiome clone } \\
\text { ncd365c05c1 (HM313304, } 100 \%)\end{array}$ \\
\hline Shewanella_s & 3 & 2 & $\begin{array}{l}\text { Shewanella algae strain CD13 (KC210859, } 100 \% \text { ) Roach intestine clone Z2_S_KL_412 (KC337222, } \\
100 \%)\end{array}$ \\
\hline Ralstonia_g & 2 & 3 & $\begin{array}{l}\text { Hydrothermal chimney clone P5-b58 (FR853020, } 100 \% \text { ) Ralstonia solanacearum strain in4ss52 (from } \\
\text { soil) (JQ655458, } 99 \%)\end{array}$ \\
\hline Prochlorococcus_g & 2 & 4 & $\begin{array}{l}\text { Gulf of Trieste clone BF2010_Jul_5m_H5 (JX864780, } 100 \% \text { ) Synechococcus sp. KUAC } 3035 \\
\text { (HQ533223, } 100 \%)\end{array}$ \\
\hline Comamonadaceae_f & 2 & 68 & $\begin{array}{l}\text { Lake bacterioplankton DGGE gel band FSW-Lt05-15 (GU734074, } 100 \%) \text { Amazon River clone } \\
\text { 4P_002a_H02 (JX672510, } 99 \%)\end{array}$ \\
\hline Jeotgalicoccus_s & 2 & 393 & $\begin{array}{l}\text { Air sample clone XXM_1_036 (JX559182, } 99 \% \text { ) Skin microbiome clone ncd2808e06c1 (JF240832, } \\
99 \%)\end{array}$ \\
\hline Comamonadaceae_f & 1 & 203 & $\begin{array}{l}\text { Salton Sea clone DSFBPENV11bac_1D (KC465634, } 99 \%) \text { Soil clone GYn3-13 associated with Mn- } \\
\text { Fe nodules (JX493061, } 99 \%)\end{array}$ \\
\hline Cupriavidus_g & 1 & 5 & $\begin{array}{l}\text { Cupriavidus sp. MA09 (Atlantic forest soil) (KC111958, } 99 \% \text { ) Cupriavidus sp. CHP-YG38 (from soil) } \\
\text { (JX965398, } 99 \%)\end{array}$ \\
\hline Lactococcuslacti_s & 1 & 6 & $\begin{array}{l}\text { Lactococcus lactis subsp. lactis Il1403 (KC429785, } 100 \%) \text { Wastewater treatment clone } \\
\text { SludgeG_upper_64 (AB515615, } 100 \%)\end{array}$ \\
\hline Gomphosphaeriaceae_f & 1 & 7 & $\begin{array}{l}\text { Synechocystis sp. PCC } 6803 \text { (freshwater) (CP00326,5 98 \%) Aphanocapsa cf. rivularis UAM } 390 \\
\text { (freshwater) (JQ070058, } 98 \% \text { ) }\end{array}$ \\
\hline Gammaproteobacteria_c & 1 & 8 & $\begin{array}{l}\text { Geothermal water clone Tat-08-009_43_53 (GU437483, } 100 \% \text { ) Coastal microbial mat clone clone } \\
\text { GBII-44 (GQ441315, 100\%) }\end{array}$ \\
\hline
\end{tabular}

Taxonomic classification was assigned using the RDP classifier and retrained with the Greengenes taxonomy. The highest level of classification for each OTU is indicated as follows: $\mathrm{c}=$ class, $\mathrm{f}=$ family, $\mathrm{g}=$ genus, and $\mathrm{s}=$ species. Abundance was calculated as a percentage of the total sequences meeting the quality standards $(20,500)$

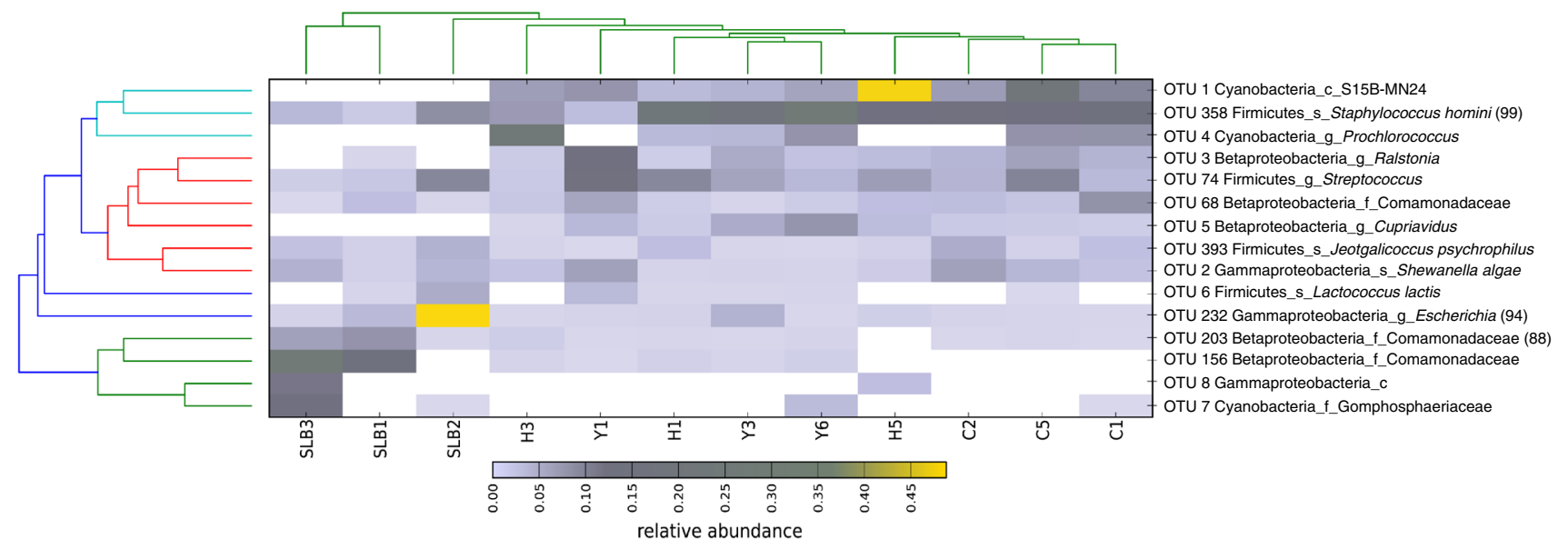

Fig. 3 Heat map demonstrating the relative abundance of the 15 most abundant OTUs. Sequences were acquired from climbing wall holds sampled in gyms in either a rural setting (SLB) or the greater Boston, MA-area $(C, Y$, and $H)$. Both axes are clustered based on the BrayCurtis dissimilarity metric. Taxonomic identification begins with phylum-level (or class level for Proteobacteria) classification followed by the highest-level taxonomic classification for each OTU ( $\mathrm{c}=$ class, $\mathrm{f}=$ family, $\mathrm{g}=$ genus, $\mathrm{s}=$ species $)$, assigned using the RDP classifier and retrained with the Greengenes taxonomy. All taxonomic assignments by the RDP classifier indicate $100 \%$ confidence unless otherwise stated 


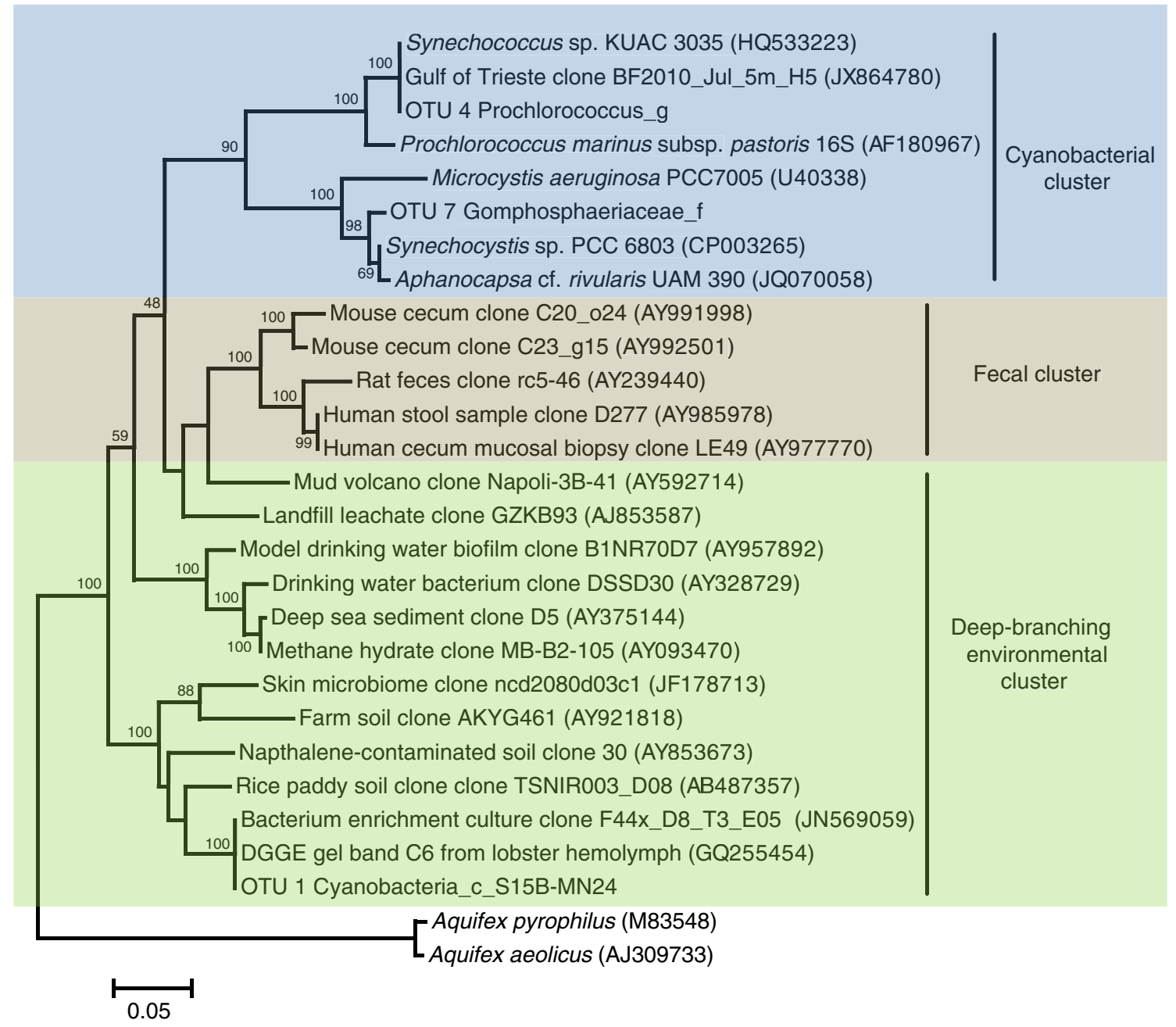

Fig. 4 Neighbor-joining dendrogram showing representative cyanobacterial sequences (OTU 1, OTU 4, and OTU 7) found on climbing wall holds in this study and sequences from top blast hits compared to other cyanobacterial sequences in the literature, including deepbranching clades of sequences detected in either fecal/colon/cecal

abundance of cyanobacterial sequences in offices in the two coastal cities, New York, NY and San Francisco, CA and virtually absent in office spaces in the inland city, Tuscon, AZ [26].

Interestingly, the most abundant cyanobacterial sequence (OTU 1) clustered closely with sequences of environmental origin [Accession AY328729, 55] and were distinct from those of fecal or cecal [Accession AY991998, 35] origin (Fig. 4). This sequence also shared $100 \%$ identity (over ca. $374 \mathrm{nt}$ ) to a sequence obtained from lobster hemolymph (Table 2) and was abundant in all nine Boston-area holds (2-40\%), but completely absent from all three inland holds (Fig. 3), suggesting that this OTU may be marine derived. samples, skin samples, or environmental samples. Alignments were generated using SILVA [43], and dendrograms were calculated using PHYLIP [17]. Bootstrapping values are shown only for nodes that were supported by both maximum-likelihood and neighbor-joining analyses. Aquifex spp. were used to create the outgroup

Skin, Oral, and Fecal Indicators

A modest skin signature was apparent. For example, several of the bacterial groups found to be abundant on hand surfaces (Fierer et al. 2008) were also abundant on climbing holds including Streptococcaceae, Burkhoderiales, and Staphylococcaceae, while other groups that are rare on hand surfaces were abundant on climbing holds such as Halomonadaceae, Veilonellaceae, and Enterobacteriaceae. More importantly, three of the top 15 most abundant OTUs had top Blast hits that are skin associated: (1) OTU 358, representing $8 \%$ of sequences, was $100 \%$ identical to Staphylococcus epidermidis strain BY3, (2) OTU 156 , representing $4 \%$ of sequences, was $100 \%$ 
identical to Skin microbiome clone ncd365c05c1, and (3) OTU 393, representing $2 \%$ of sequences, was $99 \%$ identical to Skin microbiome clone ncd2808e $06 \mathrm{c} 1$ (Table 2).

Sequences assigned to the genus Escherichia (OTU 232) represented $9 \%$ of the total sequences retrieved and were detected on all 12 holds (Figs. 2, 3; Table 2). This OTU represented up to $43 \%$ of sequences found on hold SLB2, suggesting that proportionately large numbers of enteric bacteria can be found on climbing holds (Fig. 2; Table 2). Hold SLB2 not only had the highest DNA yield of all the holds (ca. $4 \mu \mathrm{g}$ ), but additionally an independent primer set revealed that Enterobacteriaceae-related sequences represented approximately $23 \%$ of the total sequences on this hold. In the pyrosequencing analysis, Shigella/Escherichia spp. related sequences represented at least $13 \%$ of the total sequences across all 12 holds or roughly $56 \%$ of the sequences on hold SLB2. This is an important finding given that some pathogenic enterics, such as $\mathrm{O} 157: \mathrm{H} 7$ [23] and Shigella [30], have a low infectious dose [15, 27]. It is unclear whether the Escherichia spp. sequences obtained here are of human or animal origin, but at least one other study has found an abundance of fecal indicator bacteria from household pets (dogs) in outdoor air [7], corroborating the hypothesis that fecal bacteria [also known as a "fecal veneer" 15] may be prevalent in human environments. Finally, roughly $5 \%$ of the sequences detected across all holds were potentially of oral origin including OTU 74 (1,018 sequences; detected on all 12 holds), which was $100 \%$ identical to Streptococcus oralis strain HV 0s122 and OTU 763 (2 sequences), which was $100 \%$ identical to the common oral microbe Porphyromonas gingivalis.

\section{Conclusions}

Our results indicate dispersal of microorganisms from climbing shoes, hands, and environmental sources, with less input from human sources on climbing holds compared to other built environments. Because human-associated microbial communities typically contain a higher abundance of human pathogens and/or opportunistic pathogens [32], one might infer that, due to the greater environmental signature detected here, climbing holds potentially pose less of a health risk compared to other indoor environments. In summary, all twelve holds examined contained evidence of microorganisms associated with fecal material. Sequences associated with fecal microorganisms represented roughly $9 \%$ of all sequences, including as many as $43 \%$ of the sequences associated with a single climbing hold. While this does not necessarily represent a significant risk, climbers should take precautions, for example, by washing their hands both before and after climbing.
Acknowledgments This research was performed, in part, by participants in the MBL Microbial Diversity Course in Woods Hole, MA, and was supported in part by the Howard Hughes Medical Foundation, the Gordon and Betty Moore Foundation (2493), the National Science Foundation (DEB-091799), the US Department of Energy (DE-FG02-10ER13361), and the NASA Astrobiology Institute. We thank Carey (Trey) Snellings for assistance with culturing conducted at Appalachian State University. Finally, we want to acknowledge four anonymous climbing gym facility managers for allowing us to sample holds and climbing routes.

\section{References}

1. Altschul SF, Gish W, Miller W, Myers EW, Lipman DJ (1990) Basic local alignment search tool. J Mol Biol 215:403-410

2. Archibald LK, Shapiro J, Pass A, Rand K, Southwick F (2008) Methicillin-resistant Staphylococcus aureus infection in a college football team: risk factors outside the locker room and playing field. Infect Control Hosp Epidemiol 29:450-453

3. Bartley JM, Olmsted RN (2008) Reservoirs of pathogens causing health care-associated infections in the 21st Century: is renewed attention to inanimate surfaces warranted? Clin Microbiol Newslett 30:113-117

4. Bloomfield SF, Stanwell-Smith R, Crevel RWR, Pickup J (2006) Too clean, or not too clean: the hygiene hypothesis and home hygiene. Clin Exp Allergy 36:402-425

5. Boone SA, Gerba CP (2007) Significance of fomites in the spread of respiratory and enteric viral disease. Appl Environ Microbiol 73:1687-1696

6. Bowers AL, Huffman GR, Sennett BJ (2008) Methicillin-resistant Staphylococcus aureus infections in collegiate football players. Med Sci Sports Exerc 40:1362-1367

7. Bowers RM, Sullivan AP, Costello EK, Collett JL, Knight R, Fierer N (2011) Sources of bacteria in outdoor air across cities in the midwestern United States. Appl Environ Microbiol 77:6350-6356

8. Caporaso JG, Kuczynski J, Stombaugh J, Bittinger K, Bushman FD, Costello EK, Fierer N, Pena AG, Goodrich JK, Gordon JI, Huttley GA, Kelley ST, Knights D, Koenig JE, Ley RE, Lozupone CA, McDonald D, Muegge BD, Pirrung M, Reeder J, Sevinsky JR, Tumbaugh PJ, Walters WA, Widmann J, Yatsunenko T, Zaneveld J, Knight R (2010) QIIME allows analysis of highthroughput community sequencing data. Nat Methods 7:335-336

9. Casewell M, Phillips I (1977) Hands as route of transmission for Klebsiella species. BMJ 2:1315-1317

10. CDC (2009) Methicillin-resistant Staphylococcus aureus among players on a high school football team- New York City, 2007. Morb Mortal Wkly Rep 58:52-55

11. Cohen PR (2005) Cutaneous community-acquired methicillinresistant Staphylococcus aureus infection in participants of athletic activities. South Med Assoc 98:596-602

12. Cohen PR (2008) The skin in the gym: a comprehensive review of the cutaneous manifestations of community-acquired methicillin-resistant Staphylococcus aureus infection in athletes. Clin Dermatol 26:16-26

13. DeSantis T Jr, Hugenholtz P, Keller K, Brodie E, Larsen N, Piceno Y, Phan R, Andersen G (2006) NAST: a multiple sequence alignment server for comparative analysis of 16S rRNA genes. Nucleic Acids Res 34:W394-W399

14. Dethlefsen L, McFall-Ngai M, Relman DA (2007) An ecological and evolutionary perspective on human-microbe mutualism and disease. Nature 449:811-818

15. Donskey CJ (2010) Preventing transmission of Clostridium difficile: is the answer blowing in the wind? Clin Infect Dis 50:1458-1461 
16. Dybwad M, Skogan G, Blatny JM (2014) Temporal variability of the bioaerosol background at a subway station: concentration level, size distribution, and diversity of airborne bacteria. Appl Environ Microbiol 80:257-270

17. Felsenstein J (2004) PHYLIP (Phylogeny Inference Package) version 3.68.Distributed by the author Department of Genome Sciences, University of Washington, Seattle

18. Fierer N, Hamady M, Lauber CL, Knight R (2008) The influence of sex, handedness, and washing on the diversity of hand surface bacteria. Proc Natl Acad Sci USA 105:17994-17999

19. Fierer N, Lauber CL, Zhou N, McDonald D, Costello EK, Knight R (2010) Forensic identification using skin bacterial communities. Proc Natl Acad Sci USA 107:6477-6481

20. Flores GE, Bates ST, Knights D, Lauber CL, Stombaugh J, Knight R, Fierer N (2011) Microbial biogeography of public restroom surfaces. PLoS One 6:e28132

21. Flores GE, Bates ST, Caporaso JG, Lauber CL, Leff JW, Knight R, Fierer N (2013) Diversity, distribution and sources of bacteria in residential kitchens. Environ Microbiol 15:588-596

22. Gihring TM, Green SJ, Schadt CW (2012) Massively parallel rRNA gene sequencing exacerbates the potential for biased community diversity comparisons due to variable library sizes. Environ Microbiol 14:285-290

23. Grad YH, Lipsitch M, Feldgarden M, Arachchi HM, Cerqueira GC, FitzGerald M, Godfrey P, Haas BJ, Murphy CI, Russ C (2012) Genomic epidemiology of the Escherichia coli O104: H4 outbreaks in Europe, 2011. Proc Natl Acad Sci USA 109: 3065-3070

24. Gwaltney JM, Moskalski PB, Hendley JO (1978) Hand-to-hand transmission of rhinovirus colds. Ann Intern Med 88:463-467

25. Henderson DK (2006) Managing methicillin-resistant staphylococci: a paradigm for preventing nosocomial transmission of resistant organisms. Am J Infect Control 34:S46-S54

26. Hewitt KM, Gerba CP, Maxwell SL, Kelley ST (2012) Office space bacterial abundance and diversity in three metropolitan areas. PLoS One 7:e37849

27. Hewitt KM, Mannino FL, Gonzalez A, Chase JH, Caporaso JG, Knight R, Kelley ST (2013) Bacterial diversity in two neonatal intensive care units (NICUs). PLoS One 8:e54703

28. Hospodsky D, Qian J, Nazaroff WW, Yamamoto N, Bibby K, Rismani-Yazdi H, Peccia J (2012) Human occupancy as a source of indoor airborne bacteria. PLoS One 7:e34867

29. Judah G, Donachie P, Cobb E, Schmidt W, Holland M, Curtis V (2010) Dirty hands: bacteria of faecal origin on commuters' hands. Epidemiol Infect 138:409

30. Karlsson MS, Bowen A, Reporter R, Folster JP, Grass JE, Howie RL, Taylor J, Whichard JM (2013) Outbreak of infections caused by Shigella sonnei with reduced susceptibility to azithromycin in the United States. Antimicrob Agents Chemother 57:1559-1560

31. Kelley S, Gilbert J (2013) Studying the microbiology of the indoor environment. Genome Biol 14:202

32. Kembel SW, Jones E, Kline J, Northcutt D, Stenson J, Womack AM, Bohannan BJM, Brown GZ, Green JL (2012) Architectural design influences the diversity and structure of the built environment microbiome. ISME J 6:1469-1479

33. Klepeis NE, Nelson WC, Ott WR, Robinson JP, Tsang AM, Switzer P, Behar JV, Hern SC, Engelmann WH (2001) The National Human Activity Pattern Survey (NHAPS): a resource for assessing exposure to environmental pollutants. J Expo Anal Environ Epidemiol 11:231-252

34. Leech JA, Nelson WC, Burnett RT, Aaron S, Raizenne ME (2002) It's about time: a comparison of Canadian and American timeactivity patterns. J Expo Anal Environ Epidemiol 12:427-432

35. Ley RE, Bäckhed F, Turnbaugh P, Lozupone CA, Knight RD, Gordon JI (2005) Obesity alters gut microbial ecology. Proc Natl Acad Sci USA 102:11070-11075
36. Lopman B, Gastañaduy P, Park GW, Hall AJ, Parashar UD, Vinjé J (2012) Environmental transmission of norovirus gastroenteritis. Curr Opin Virol 2:96-102

37. Mbithi JN, Springthorpe VS, Boulet JR, Sattar SA (1992) Survival of hepatitis A virus on human hands and its transfer on contact with animate and inanimate surfaces. J Clin Microbiol 30:757-763

38. Meadow JF, Altrichter AE, Kembel SW, Kline J, Mhuireach G, Moriyama M, Northcutt D, O'Connor TK, Womack AM, Brown GZ, Green JL, Bohannan BJM (2014) Indoor airborne bacterial communities are influenced by ventilation, occupancy, and outdoor air source. Indoor Air 24:41-48

39. Mukherjee DV, Cohen B, Bovino ME, Desai S, Whittier S, Larson EL (2012) Survival of influenza virus on hands and fomites in community and laboratory settings. Am J Infect Control 40:590

40. Naether A, Foesel BU, Naegele V, Wüst PK, Weinert J, Bonkowski M, Alt F, Oelmann Y, Polle A, Lohaus G (2012) Environmental factors affect acidobacterial communities below the subgroup level in grassland and forest soils. Appl Environ Microbiol 78:7398-7406

41. Osburn MR, Sessions AL, Pepe-Ranney C, Spear JR (2011) Hydrogen-isotopic variability in fatty acids from Yellowstone National Park hot spring microbial communities. Geochim Cosmochim Acta 75:4830-4845

42. Patel A, Fischer S, Calfee R, Plante M, Fadale P (2007) Locker room acquired methicillin-resistant Staphylococcus aureus. Orthopedics 30

43. Pruesse E, Quast C, Knittel K, Fuchs BM, Ludwig W, Peplies J, Glöckner F (2007) SILVA: a comprehensive online resource for quality checked and aligned ribosomal RNA sequence data compatible with ARB. Nucleic Acids Res 35:7188-7196

44. Reeder J, Knight R (2010) Rapid denoising of pyrosequencing amplicon data: exploiting the rank-abundance distribution. Nat Methods 7:668

45. Reynolds CS (2006) The ecology of phytoplankton. Cambridge University Press, Cambridge, p 552

46. Rintala H, Pitkaeranta M, Toivola M, Paulin L, Nevalainen A (2008) Diversity and seasonal dynamics of bacterial community in indoor environment. BMC Microbiol 8:56

47. Robertson CE, Baumgartner LK, Harris JK, Peterson KL, Stevens MJ, Frank DN, Pace NR (2013) Culture-independent analysis of aerosol microbiology in a metropolitan subway system. Appl Environ Microbiol 79:3485-3493

48. Schloss PD, Westcott SL, Ryabin T, Hall JR, Hartmann M, Hollister EB, Lesniewski RA, Oakley BB, Parks DH, Robinson CJ (2009) Introducing mothur: open-source, platform-independent, community-supported software for describing and comparing microbial communities. Appl Environ Microbiol 75:7537-7541

49. Schloss PD, Gevers D, Westcott SL (2011) Reducing the effects of PCR amplification and sequencing artifacts on 16S rRNAbased studies. PLoS One 6:e27310

50. Schoffl V, Morrison A, Kupper T (2011) Risk of transmission of blood borne infections in climbing: consensus statement of UIAA Medcom. Int J Sports Med 32:170-173

51. Stevens DL, Bisno AL, Chambers HF, Everett ED, Dellinger P, Goldstein EJC, Gorbach SL, Hirschmann JV, Kaplan EL, Montoya JG, Wade JC (2005) Practice guidelines for the diagnosis and management of skin and soft-tissue infections. Clin Infect Dis 41:1373-1406

52. Tringe SG, Zhang T, Liu XG, Yu YT, Lee WH, Yap J, Yao F, Suan ST, Ing SK, Haynes M, Rohwer F, Wei CL, Tan P, Bristow J, Rubin EM, Ruan YJ (2008) The airborne metagenome in an indoor urban environment. PLoS One 3:e1862

53. Wang Q, Garrity GM, Tiedje JM, Cole JR (2007) Naive Bayesian classifier for rapid assignment of rRNA sequences into the new bacterial taxonomy. Appl Environ Microbiol 73:5261-5267 
54. Wertheim HFL, Melles DC, Vos MC, van Leeuwen W, van Belkum A, Verbrugh HA, Nouwen JL (2005) The role of nasal carriage in Staphylococcus aureus infections. The Lancet 5:751-762
55. Williams M, Domingo J, Meckes M, Kelty C, Rochon H (2004) Phylogenetic diversity of drinking water bacteria in a distribution system simulator. J Appl Microbiol 96:954-964 